\title{
Carotid Stenting and Mechanical Thrombectomy in Patients with Acute Ischemic Stroke and Tandem Occlusions: Antithrombotic Treatment and Functional Outcome
}

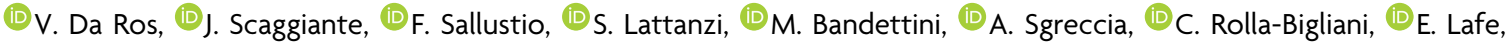

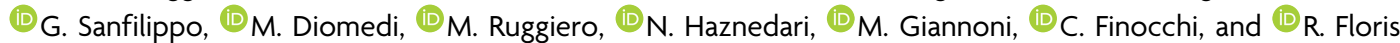

\begin{abstract}
BACKGROUND AND PURPOSE: There is no consensus on the optimal antithrombotic medication for patients with acute ischemic stroke with anterior circulation tandem occlusions treated with emergent carotid stent placement and mechanical thrombectomy. The identification of factors influencing hemorrhagic risks can assist in creating appropriate therapeutic algorithms for such patients. This study aimed to investigate the impact of medical therapy on functional and safety outcomes in patients treated with carotid stent placement and mechanical thrombectomy for tandem occlusions.
\end{abstract}

MATERIALS AND METHODS: A multicenter retrospective study on prospectively collected data was conducted. Only patients treated with carotid stent placement and mechanical thrombectomy for tandem occlusions of the anterior circulation were included. Univariate and multivariate analyses were performed on preprocedural, procedural, and postprocedural variables to assess factors influencing clinical outcome, symptomatic intracranial hemorrhage, stent patency, and successful intracranial vessel recanalization.

RESULTS: Ninety-five patients with acute ischemic stroke and tandem occlusions were included. Good clinical outcome (mRS $\leq 2$ ) at 3 months was reached by 33 (39.3\%) patients and was associated with baseline ASPECTS $\geq 8(\mathrm{OR}=1.53 ; 95 \% \mathrm{Cl}, 1.16-2.00)$, $\leq 2$ mechanical thrombectomy attempts $(\mathrm{OR}=0.71 ; 95 \% \mathrm{Cl}, 0.55-0.99)$, and the absence of symptomatic intracranial hemorrhage $(\mathrm{OR}=$ $0.13 ; 95 \% \mathrm{Cl}, 0.03-0.51)$. Symptomatic intracranial hemorrhage was associated with a higher amount of intraprocedural heparin, ASPECTS $\leq 7$, and $\geq 3$ mechanical thrombectomy attempts. No relationships among types of acute antiplatelet regimen, intravenous thrombolysis, and symptomatic intracranial hemorrhage were observed. Patients receiving dual-antiplatelet therapy after hemorrhagic transformation had been ruled out on 24-hour CT were more likely to achieve functional independence and had a lower risk of symptomatic intracranial hemorrhage.

CONCLUSIONS: During carotid stent placement and mechanical thrombectomy for tandem occlusion treatment, higher intraprocedural heparin dosage ( $\geq 3000 \mathrm{IU}$ ) increased symptomatic intracranial hemorrhage risk when the initial ASPECTS was $\leq 7$, and mechanical thrombectomy needs more than one passage for complete recanalization. Antiplatelets antiplatelets use were safe, and dual-antiaggregation therapy was related to better functional outcomes.

ABBREVIATIONS: AIS = acute ischemic stroke; $\mathrm{ICH}=$ intracranial hemorrhage; $\mathrm{MT}=$ mechanical thrombectomy; sICH = symptomatic intracranial hemorrhage; $\mathrm{TO}=$ tandem occlusion

$\mathbf{T}$ andem occlusions (TOs) occur in up to $16 \%-20 \%$ of patients with acute ischemic stroke of the anterior cerebral circulation and are defined as a combined extracranial-intracranial cervical

\section{Received April 21, 2020; accepted after revision July 7.}

From the Department of Biomedicine and Prevention (V.D.R., J.S., R.F.), Interventional Neuroradiology Unit, and Comprehensive Stroke Center (F.S., M.D.), Department of Systems Medicine, University of Rome Tor Vergata, Rome, Italy; Neurological Clinic (S.L.), Department of Experimental and Clinical Medicine, Marche Polytechnic University, Ancona, Italy; Neurological Clinic (M.B., C.F.), Department of Neurosciences and Interventional Neuroradiology Unit (A.S., E.L., G.S.), IRCCS Policlinico San Matteo, Pavia, Italy; Department of Diagnostic and Interventional Neuroradiology (C.R.-B.), Policlinico Universitario, San Martino, Italy; Neuroradiology Unit (M.R., N.H.), AUSL Romagna, Cesena, Italy; and

Neuroradiological Clinic (M.G.), Department of Radiological Sciences, AOU Ospedali Riuniti, Ancona, Italy.

V.D. Ros and J. Scaggiante contributed equally to the article.
ICA lesion (complete occlusion or $\geq 90 \%$ stenosis according to the $\mathrm{NASCET}^{1}$ criteria) and ipsilateral occlusion of proximal intracranial large vessels (ICA, the M1 and/or M2 segment of the middle cerebral artery) ${ }^{2}$

Acute ischemic stroke (AIS) caused by TOs is generally associated with a poor prognosis when left untreated. ${ }^{3}$

Please address correspondence to Valerio Da Ros, MD, Department of Biomedicine, Interventional Neuroradiology unit, University of Rome Tor Vergata, Viale Oxford 81, Rome, Italy; e-mail: darosvalerio@gmail.com 
Although intravenous thrombolysis with tPA remains part of the criterion standard treatment, ${ }^{4}$ tandem occlusions respond poorly to intravenous thrombolysis alone, ${ }^{5}$ likely due to the poor responsiveness of large thrombi to enzymatic digestion. Because intracranial vessel recanalization is the most powerful predictor of favorable clinical outcome, ${ }^{6}$ endovascular therapy is the standard of care for tandem occlusions. ${ }^{7}$ However, the most appropriate interventional strategy to manage the extracranial carotid disease remains controversial. ${ }^{2,7-11}$

Systematic reviews ${ }^{12}$ and post hoc analyses ${ }^{13}$ reported similar clinical outcomes at 3-month follow-up in patients with acute ischemic stroke and tandem occlusions treated with carotid stent placement or angioplasty. Conversely, a recent meta-analysis, ${ }^{14}$ a prospective nonrandomized trial, ${ }^{15}$ and the international multicenter Thrombectomy in TANdem Occlusion (TITAN) and Systematic Evaluation of Patients Treated with Stroke Devices for Acute Ischemic Stroke (STRATIS) Registry ${ }^{16-18}$ suggested better outcomes and higher recanalization rates for patients undergoing carotid stent placement.

The best antiplatelet/anticoagulant management to reduce the risk of postinterventional symptomatic intracranial hemorrhage $(\mathrm{sICH})$ and prevent stent re-occlusion in these patients remains a matter of ongoing debate. Because emergent carotid stent placement during acute ischemic stroke requires antithrombotic agents, this strategy may be less appealing due to the intracranial hemorrhage (ICH) risk, especially for patients already receiving intravenous thrombolysis. ${ }^{19}$ Moreover, as addressed by the TITAN investigators, the use of intraprocedural heparin in tandem occlusions failed to demonstrate better functional, angiographic, or safety outcomes. ${ }^{20}$ So far, little evidence exists to guide the medical therapy of tandem occlusions treated with carotid stent placement, ${ }^{21}$ and high-quality analyses and randomized controlled trials are needed. ${ }^{22}$

This study aimed to investigate the impact of medical therapy on functional and safety outcomes in patients treated with carotid stent placement and mechanical thrombectomy for tandem occlusions.

\section{MATERIALS AND METHODS Study Design}

We retrospectively evaluated all consecutive patients admitted with acute ischemic stroke between January 2018 and December 2019 in 5 Italian neurointerventional centers.

We included in this study only patients treated with emergent carotid stent placement and mechanical thrombectomy for a tandem occlusion, defined as an extracranial ICA lesion (complete occlusion or $\geq 90 \%$ stenosis according to the NASCET $^{1}$ criteria) and an ipsilateral proximal intracranial large-vessel occlusion (intracranial ICA, the M1 and/or M2 segment of the middle cerebral artery) confirmed at initial cerebral angiography. Eligibility for intravenous thrombolysis and endovascular treatment was evaluated at each center according to the American Heart Association/ American Stroke Association guidelines.

Preprocedural, procedural, 24- to 48-hour postprocedural, discharge, and 3-month data were prospectively collected. No ethics committee approval was required for this retrospective observational study.
We evaluated the following variables: demographic characteristics (ie, age, sex), cardiovascular risk factors (ie, atrial fibrillation, arterial hypertension, diabetes mellitus, hypercholesterolemia, smoking, previous cardio-cerebrovascular accidents), clinical and radiologic assessments (ie, mRS, ${ }^{23}$ NIHSS score,${ }^{24}$ imaging characteristics [ie, ASPECTS]), ${ }^{25}$ stroke etiology according to the Trial of Org 10172 in Acute Stroke Treatment (TOAST) classification, ${ }^{26}$ stroke side, hemorrhagic transformation, stent patency, procedural time, (ie, onset-to-groin time, onset-to-recanalization time), number of mechanical thrombectomy (MT) attempts, type of stent (singleor dual-layer), and medical therapy (ie, preprocedural medications, intra- and postprocedural anticoagulant/antiplatelet protocols).

Good clinical outcome was defined as mRS 0-2 at 3-month follow-up, and favorable clinical outcome, as mRS 0-3.

\section{Imaging Evaluation}

All CT scans were obtained with 64 slices using a helicoid acquisition (GE LightSpeed VCT 64; GE Healthcare). At each institution, 2 neurointerventional radiologists independently analyzed preprocedural CT scans. Any disagreement was resolved by consensus with a third neuroradiologist (ie, head of the department). The cervical ICA occlusion was included in the TOAST classification on DSA, according to clinical and angiographic imaging characteristics. Successful recanalization was defined as modified TICI $2 b-3$ on DSA. $^{27}$

CT angiography was used to assess stent patency within 72 hours from treatment. Acute in-stent occlusion was defined as occlusion of the carotid stent within 72 hours after stent placement.

Symptomatic intracranial hemorrhage $(\mathrm{sICH})$ was defined as parenchymal hematoma type 1 or 2 using the European Cooperative Acute Stroke Study (ECASS) III grading, according to imaging at 24 hours, associated with an increase of at least 4 NIHSS points within 24 hours, or resulting in death. ${ }^{28}$

\section{Emergent Carotid Stent Placement and MT}

There were no technical restrictions to perform cervical ICA stent placement and intracerebral mechanical thrombectomy. Each center independently decided the stent type (ie, single-layer stent or dual-layer stent) and the mechanical thrombectomy technique (ie, aspiration and/or stent retriever) according to their experience.

\section{Anticoagulation/Antiaggregation}

For each patient, we assessed preprocedural, intraprocedural, and postprocedural medications, independently decided at each institution.

IV heparin sodium use was administered at the discretion of each center. The total amount of IV heparin was calculated on the basis of the speed of infusion, use of a bolus, and time from first infusion to the end of the procedure.

In patients already receiving antiplatelet medications, a singleantiplatelet therapy was defined as a regular dosage of aspirin (Bayer) (ie, up to $300 \mathrm{mg}$ ) or clopidogrel $75 \mathrm{mg}$. In patients without antiplatelet medication, a dose of $500 \mathrm{mg}$ of intravenous lysine acetylsalicylate administered before deployment of carotid stent placement was considered a regular single dosage. Dualantiplatelet therapy was defined as a treatment with combined 


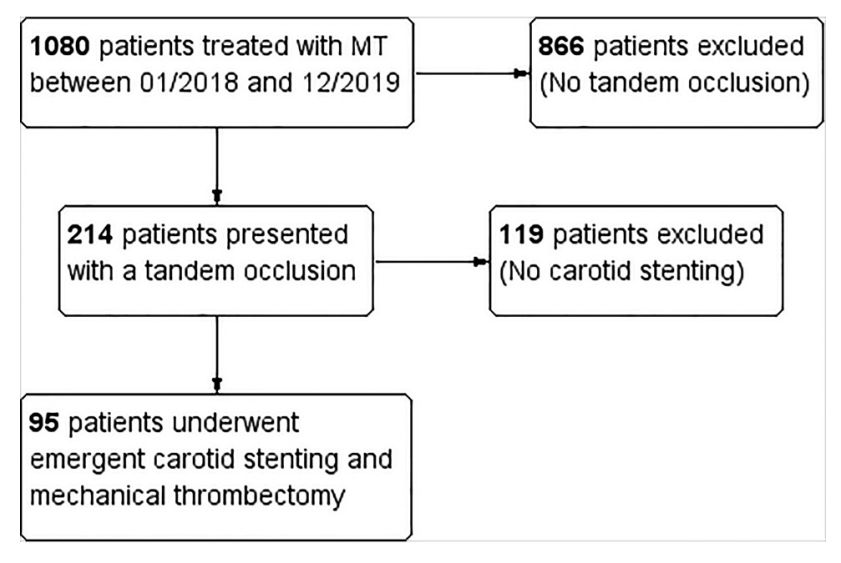

FIGURE. Flow chart of the study population.

elimination procedure; a separate ANOVA was conducted for each dependent variable at an $\alpha$ level of .025. Analyses were performed using SPSS, Version 23.0 (IBM).

\section{RESULTS}

\section{Study Population}

Between January 2018 and December 2019, one thousand eighty patients admitted with acute ischemic stroke underwent mechanical thrombectomy; 214 patients (19.8\%) presented with extracranial/intracranial tandem occlusions, of whom 95 patients $(44.4 \%)$ received emergent carotid stent placement (flow chart in the Figure). The characteristics of the study population are presented in Table 1.

Fifty-six patients (58.9\%) presented with a left-hemispheric stroke. Median baseline ASPECTS was 8, and the NIHSS score was

16.8. Forty-five patients (47.4\%) were treated with mechanical thrombectomy plus intravenous thrombolysis. The mean onset-to-groin time was $284.5 \pm$ 156.4 minutes, the mean onset-to-recanalization time was $376.7 \pm$ 168.3 minutes, and the mean procedural time was $90.6 \pm 58.2$ minutes.

\section{Clinical and Angiographic Outcomes}

A successful intracranial recanalization (modified TICI 2b-3) was achieved in 58 of 95 patients (61.1\%): TICI 3 in 31 (32.6\%), TICI $2 \mathrm{c}$ in 5 (5.3\%), and TICI $2 \mathrm{~b}$ in $22(23.2 \%)$. The rate of unsuccessful recanalization was $38.9 \%$ : TICI $2 \mathrm{a}$ in 28 patients (29.5\%), TICI 1 in 3 (3.2\%), and TICI 0 in $6.3 \%$.

The rate of postprocedural sICH was $27.7 \%$. Parenchymal hematoma type 1 occurred in 12 (12.7\%) patients, and parenchymal hematoma type 2 , in $14(14.9 \%)$ patients. Clinical follow-up at 3 months from stroke was available in 84 patients: Thirty-three (39.3\%) were functionally independent (mRS $0-2)$, and 47 (56\%) achieved a favor-

able outcome (mRS 0-3).

medications (eg, aspirin with clopidogrel) or a double regular dose of a single drug (eg, lysine acetylsalicylate, $1000 \mathrm{mg}$ ).

\section{Statistical Analysis}

Continuous variables were reported as mean \pm SD or median with range, and categoric variables, as number and percentage. Contingency analyses for categoric variables were performed using the exact $\chi^{2}$ test.

Group comparisons were performed with the ANOVA and univariate logistic regression analyses to identify factors influencing clinical outcomes, stent patency, successful revascularization, and sICH. A 2 -sided $P$ value $<.05$ indicated statistical significance. The multivariate analysis was performed using a general linear regression model (MANOVA), with a stepwise backward

\section{Management of Tandem Lesions}

Emergent carotid artery stent placement was performed in all patients. In 87 patients, a single-layer carotid stent was used, and 8 patients were treated with a dual-layer carotid stent.

\section{Factors Influencing Clinical Outcomes: ANOVA, Univariate, and Multivariate Analyses}

The subgroup comparison of patients with functional independence (mRS 0-2) and dependence at 3-month follow-up is presented in On-line Table 1. Patients with good clinical outcome were younger (mean age, 61.4 versus 65.9 years), presented with shorter onset-to-recanalization time (median, 317.5 versus 
360 minutes), had a higher rate of successful intracerebral recanalization (modified TICI $\geq 2$ b: $75.8 \%$ versus $52.9 \%$ ), were more commonly prescribed postprocedural dual-antiplatelet therapy (67.9\% versus $25.9 \%$ ), and showed lower rates of sICH (9.1\% versus $42 \%)$. All other cofactors were not statistically different between groups. The univariate logistic regression analysis is presented in On-line Table 2.

Factors associated with a good clinical outcome were higher baseline ASPECTS (OR $=1.53$; 95\% CI , 1.16-2; $P=.002)$, lower rates of $\operatorname{sICH}(\mathrm{OR}=0.13 ; 95 \% \mathrm{CI}, 0.37-0.51 ; P=.001)$, and $\leq 2$ MT attempts $(\mathrm{OR}=0.71 ; 95 \% \mathrm{CI}, 0.55-0.99 ; P=.04)$. Moreover, those patients receiving dual-antiplatelet therapy after hemorrhagic transformation had been ruled out on 24-hour CT had higher chances of functional independence at 3-month follow-up $(\mathrm{OR}=6.03$; 95\% CI, 1.87-19.44; $P=.003)$.

All other intraprocedural or postprocedural anticoagulant/antiplatelet protocols were not associated with good clinical outcome.

The multivariate general linear analysis (MANOVA) reported a relevant difference between patients with and without good clinical outcome when considered jointly on the variables of baseline ASPECTS, sICH, postprocedural dual-antiplatelet therapy, and number of MT attempts.

There was a significant difference between patients with and without good clinical outcome on baseline ASPECTS, $F(1-53)=8.57$, $P=.001$, partial $\eta^{2}=0.14$, with functionally independent patients having higher mean ASPECTS on baseline CT (8.4 \pm 0.4; 95\% CI, 7.9-9.2) versus dependent patients (6.9 \pm 0.4 ; 95\% CI, 6-7.7).

The multivariate analysis confirmed the association with $\mathrm{sICH}$ (negative correlation; $P=.005$ ) and postprocedural dual-antiplatelet therapy (positive correlation; $P=.003$ ). Moreover, mean mechanical thrombectomy attempts of $1.9 \pm 0.3$ (95\% CI, 1.3-2.5; $P=.004)$ were associated with good clinical outcome versus dependent patients undergoing $3.2 \pm 0.3$ (95\% CI, 2.6-3.9) attempts to recanalize the intracerebral occlusion.

\section{Factors Influencing Successful Recanalization and Stent Patency: ANOVA and Univariate Analysis}

The subgroup comparison of patients with successful and unsuccessful intracerebral recanalization is presented in On-line Table 1.

The intracerebral large-vessel occlusion was more often successfully recanalized in patients presenting with left-hemispheric stroke (69\% versus 43.2\%), higher baseline ASPECTS (median, 8 versus 7), and faster onset-to-groin time (median, 236 versus 275 minutes). Moreover, a trend toward successful recanalization $(P=.052)$ was observed for patients receiving intraprocedural heparin. The univariate logistic regression analysis is presented in On-line Table 2.

The only factors associated with a successful recanalization were a left-hemispheric stroke $(\mathrm{OR}=2.91 ; 95 \% \mathrm{CI}, 1.23-6.86$; $P=.01)$ and $\leq 2$ mechanical thrombectomy attempts $(\mathrm{OR}=0.69$; 95\% CI, 0.51-0.93; $P=.01$ ).

The comparison of the available data on stent patency within 72 hours reported a higher rate of acute in-stent occlusion for duallayer stent compared with single-layer stent (4/5 patients versus 10/ 59 patients; $80 \%$ versus $16.9 \%$; $P<.001)$. A similar result was obtained by univariate logistic regression analysis (On-line Table 2) for dual-layer stent patency $(\mathrm{OR}=0.05 ; 95 \% \mathrm{CI}, 0.005-0.50$; $P=.007)$.

\section{Factors Influencing Symptomatic Intracerebral Hemorrhage: ANOVA, Univariate, and Multivariate Analyses}

The subgroup comparison of patients with and without $\mathrm{sICH}$ is presented in On-line Table 1. The only factor associated with $\mathrm{sICH}$ was a lower baseline ASPECTS (median, 6.5 versus 8 ) confirmed by univariate logistic regression analysis (On-line Table 2; $P=.009$ ). Moreover, those patients receiving dual-antiplatelet therapy after hemorrhagic transformation had been ruled out on 24-hour CT had less chance of $\operatorname{sICH}(\mathrm{OR}=2.4 ; 95 \% \mathrm{CI}, 1-5.8 ; P=.02)$.

The multivariate general linear analysis (MANOVA) reported a significant difference between patients with and without symptomatic ICH when considered jointly on the variables baseline ASPECTS, intraprocedural heparin, and number of mechanical thrombectomy attempts, the Wilk $\Lambda=0.8, F(3.80)=6.03$, $P=.001$, partial $\eta^{2}=0.18$.

There was a significant difference between patients with and without symptomatic ICH on baseline ASPECTS, $F(1-84)=12.17$, $P=.001$, partial $\eta^{2}=0.13$, with patients with sICH having lower ASPECTS on baseline CT (mean $=6.6 \pm 0.4 ; 95 \%$ CI, 5.8-7.4) compared with patients without $\mathrm{SICH}(8.3 \pm 0.2$; 95\% CI, 7.8-8.7).

There was a significant difference between patients with and without sICH in intraprocedural heparin administration, $F$ $(1-84)=6.4, P=.01$, partial $\eta^{2}=0.07$, with patients with sICH in patients receiving higher amounts of heparin (mean $=3547 \pm$ 588 IU; 95\% CI, 2377-4718 IU) compared with patients without sICH (1817 \pm 339 IU ; 95\% CI = 1141-2493 IU).

There was a significant difference between patients with and without symptomatic ICH in the number of mechanical thrombectomy attempts, $F(1-84)=32.14, P=.002$, partial $\eta^{2}=0.1$, with $\mathrm{sICH}$ in patients treated with a higher number of passes (mean, $3.3 \pm 0.3$; 95\% CI, 2.6-4.1) compared with those without sICH $(1.9 \pm 0.2 ; 95 \% \mathrm{CI}, 1.5-2.4)$.

\section{DISCUSSION}

In this study, we assessed functional outcome and complications in patients with acute ischemic stroke and tandem occlusions treated with emergent carotid stent placement and mechanical thrombectomy. We focused our multicenter retrospective analysis on this specific subgroup of patients with special regard for medical management to respond to the demanding questions raised after the recently reported higher successful recanalization rates and better clinical outcome in tandem occlusions managed with carotid stent placement. ${ }^{13-16}$

We found that a large ischemic core at the initial CT scan (ASPECTS $\leq 7$ ), $>2$ mechanical thrombectomy attempts, and $\geq 3000$ IU of intraprocedural heparin were significant predictors of sICH (Table 2). Functional independence was related to a small ischemic core (ASPECTS $\geq 8$ ) and with the first-passages effect (ie, successful recanalization obtained with $\leq 2$ mechanical thrombectomy attempts) (Table 2). Moreover, both single- and dual-antiplatelet therapy seem safe in emergent carotid stent placement, even if patients receive intravenous thrombolysis. Despite these results differing from those reported by van de Graaf et $\mathrm{al}^{20}{ }^{20}$ they are in accordance with the most recent data from the TITAN registry. ${ }^{29}$ 
Table 2: Multivariate analysis of factors influencing symptomatic ICH and functional independence

\begin{tabular}{lccc}
\hline \multicolumn{1}{c}{ Factors } & Mean & $95 \% \mathrm{Cl}$ & $\boldsymbol{P}$ Value \\
\hline Influencing symptomatic ICH & & & \\
Intraprocedural heparin $\geq 3000 \mathrm{IU}$ & $3547 \pm 588 \mathrm{IU}$ & $2377-4718$ & .01 \\
ASPECTS $\leq 7$ & $6.6 \pm 0.4$ & $5.8-7.4$ & .001 \\
MT attempts $\geq 3$ & $3.3 \pm 0.3$ & $2.6-4.1$ & .002 \\
Influencing functional independence (mRS $\leq 2)$ & & & \\
ASPECTS $\geq 8$ & $8.4 \pm 0.4$ & $7.9-9.2$ & .001 \\
MT attempts $\leq 2$ & $1.9 \pm 0.3$ & $1.3-2.5$ & .004 \\
\hline
\end{tabular}

small group of 8 with dual-layer stents did not allow running a powerful subgroup analysis comparing single- and dual-antiplatelet therapy in dual-layer stents.

Finally, the medical treatment strategy was left to the interventionist's discretion with heterogeneous drug dosages and administration times.

\section{CONCLUSIONS}

In the literature, there are few data to

Furthermore, patients receiving dual-antiplatelet therapy after ICH had been ruled out on postprocedural CT had higher chances of functional independence at 3 months from stroke, confirming the safety profile of antiplatelet therapy. This finding is in line with the study by Zhu et al, ${ }^{29}$ which reported a lower 90 -day mortality rate in the antiplatelet therapy group.

Regarding anticoagulation, the intraprocedural heparin dosage influenced the development of sICH. While we did not observe an increased risk of ICH (ie, hemorrhagic infarction or parenchymatous hematoma ${ }^{30}$ ) within 24 hours from treatment in patients receiving low-dose intraprocedural heparin (ie, <3000 IU), consistent with previous reports, ${ }^{20,31,32}$ low-dose heparin was not related to higher reperfusion rates. ${ }^{27}$ On the contrary, a higher dose of intraprocedural heparin (ie, $\geq 3000 \mathrm{IU}$ ) was associated with sICH without improvement in the rate of successful recanalization or stent patency.

Heparin is commonly used to reduce the risk of re-occlusion and distal embolization during endovascular treatment, ${ }^{33}$ and post hoc analyses from the Thrombectomy REvascularization of Large Vessel Occlusions in Acute Ischemic Stroke (TREVO 2) and Mechanical Embolus Removal in Cerebral Ischemia (MERCI) trials showed its utility in obtaining good functional outcome without increasing the risk of hemorrhagic complications. ${ }^{31,34}$ However, the most recent results from large multicenter registries did not find differences between patients with and without heparin treatment in terms of good outcome ${ }^{35}$ or successful revascularization rates. ${ }^{28,29,36}$

In our series, the overall sICH risk seems higher compared with the TITAN registry. ${ }^{29,37,38}$ The explanation of this discrepancy may reside in differences among the study populations. In our analysis, we included only patients who underwent emergent carotid stent placement. Thus, most of the included patients received a mixture of antiplatelet therapy, intravenous thrombolysis, and heterogeneous doses of intraprocedural heparin; in contrast, in the TITAN registry, the analysis of the effect of anticoagulants was based only on patients who received a low dose of heparin.

This multicenter analysis has some limitations. First, the observational and nonrandomized design is subject to methodologic biases inherent in this form of study. Second, although only experienced neuroradiologists assessed data at each institution, we did not confirm our findings using a core lab assessment of brain imaging. Third, despite the effort to establish a comprehensive multicenter registry, there may be a concerning risk of bias due to patients lost to follow-up and missing data in the retrospective dataset. In our study, dual-layer stents represented an independent factor related to in-stent thrombosis, as previously reported by Yilmaz et $\mathrm{al}^{39}$ however, the guide management of tandem occlusions in patients with acute ischemic stroke, and optimal antithrombotic therapy remains to be assessed for patients treated with emergent carotid artery stent placement. In our analysis, regular doses of intraprocedural heparin ( $\geq 3000 \mathrm{IU})$ were associated with $\mathrm{sICH}$, antiplatelets were safe, and dual-antiaggregation therapy was related to better functional outcomes. The current findings may inform clinical practice and provide support for a prospective randomized controlled trial aimed at assessing endovascular treatment of patients with tandem occlusions.

\section{REFERENCES}

1. Ferguson Gary G, Eliasziw M, Barr Hugh WK, et al. The North American Symptomatic Carotid Endarterectomy Trial. Stroke 1999;30:1751-58 CrossRef Medline

2. Goyal M, Demchuk AM, Menon BK, et al. Randomized assessment of rapid endovascular treatment of ischemic stroke. $N$ Engl J Med 2015;372:1019-30 CrossRef Medline

3. Rubiera M, Ribo M, Delgado-Mederos R, et al. Tandem internal carotid artery/middle cerebral artery occlusion: an independent predictor of poor outcome after systemic thrombolysis. Stroke 2006;37:2301-05 CrossRef Medline

4. Powers WJ, Rabinstein AA, Ackerson T, et al. Guidelines for the Early Management of Patients with Acute Ischemic Stroke: 2019 Update to the 2018 Guidelines for the Early Management of Acute Ischemic Stroke-A Guideline for Healthcare Professionals From the American Heart Association/American Stroke Association. Stroke 2019;50:e344418 CrossRef Medline

5. Kim YS, Garami Z, Mikulik R, et al. Early recanalization rates and clinical outcomes in patients with tandem internal carotid artery/ middle cerebral artery occlusion and isolated middle cerebral artery occlusion. Stroke 2005;36:869-71 CrossRef Medline

6. Goyal M, Menon BK, van Zwam WH, et al. Endovascular thrombectomy after large-vessel ischaemic stroke: a meta-analysis of individual patient data from five randomised trials. Lancet 2016;387:172331 CrossRef Medline

7. Bracard S, Ducrocq X, Mas JL, et al; THRACE Investigators. Mechanical thrombectomy after intravenous alteplase versus alteplase alone after stroke (THRACE): a randomised controlled trial. Lancet Neurol 2016;15:1138-47 CrossRef Medline

8. Berkhemer OA, Fransen PSS, Beumer D, et al; MR CLEAN Investigators. A randomized trial of intraarterial treatment for acute ischemic stroke. N Engl J Med 2015;372:11-20 CrossRef Medline

9. Campbell BC, Mitchell PJ, Kleinig TJ, et al. Endovascular therapy for ischemic stroke with perfusion-imaging selection. $N$ Engl J Med 2015;372:1009-18 CrossRef Medline

10. Jovin TG, Chamorro A, Cobo E, et al; REVASCAT Trial Investigators. Thrombectomy within 8 hours after symptom onset in ischemic stroke. N Engl J Med 2015;372:2296-2306 CrossRef Medline 
11. Saver JL, Goyal M, Bonafe A, et al. Stent-retriever thrombectomy after intravenous t-PA vs. t-PA alone in stroke. N Engl J Med 2015;372:228595 CrossRef Medline

12. Wilson MP, Murad MH, Krings T, et al. Management of tandem occlusions in acute ischemic stroke - intracranial versus extracranial first and extracranial stenting versus angioplasty alone: a systematic review and meta-analysis. J Neurointerv Surg 2018;10:72128 CrossRef Medline

13. Assis Z, Menon BK, Goyal M, et al. Acute ischemic stroke with tandem lesions: technical endovascular management and clinical outcomes from the ESCAPE trial. J NeuroInterv Surg 2018;10:429-33 CrossRef Medline

14. Sadeh-Gonik U, Tau N, Friehmann T, et al. Thrombectomy outcomes for acute stroke patients with anterior circulation tandem lesions: a clinical registry and an update of a systematic review with meta-analysis. Eur J Neurol 2018;25:693-700 CrossRef Medline

15. Li W, Chen Z, Dai Z, et al. Management of acute tandem occlusions: stent-retriever thrombectomy with emergency stenting or angioplasty. J Int Med Res 2018;46:2578-86 CrossRef Medline

16. Zhu F, Bracard S, Anxionnat R, et al. Impact of emergent cervical carotid stenting in tandem occlusion strokes treated by thrombectomy: a review of the TITAN collaboration. Front Neurol 2019;10:206 CrossRef Medline

17. Jadhav AP, Zaidat OO, Liebeskind DS, et al. Emergent management of tandem lesions in acute ischemic stroke. Stroke 2019;50:428-33 CrossRef Medline

18. Papanagiotou P, Haussen DC, Turjman F, et al; TITAN Investigators. Carotid stenting with antithrombotic agents and intracranial thrombectomy leads to the highest recanalization rate in patients with acute stroke with tandem lesions. JACC Cardiovasc Interv 2018;11:1290-99 CrossRef Medline

19. Jacquin G, Poppe AY, Labrie M, et al. Lack of consensus among stroke experts on the optimal management of patients with acute tandem occlusion. Stroke 2019;50:1254-56 CrossRef Medline

20. van de Graaf RA, Chalos V, Del Zoppo GJ, et al. Periprocedural antithrombotic treatment during acute mechanical thrombectomy for ischemic stroke: a systematic review. Front Neurol 2018;9:238 CrossRef Medline

21. Blassiau A, Gawlitza M, Manceau PF, et al. Mechanical thrombectomy for tandem occlusions of the internal carotid artery: results of a conservative approach for the extracranial lesion. Front Neurol 2018;9:928 CrossRef Medline

22. Thrombectomy in TANdem Occlusion. NCT03978988. 2020. clinicaltrials.gov. Accessed April 4, 2020

23. Wilson JT, Hareendran A, Grant M, et al. Improving the assessment of outcomes in stroke: use of a structured interview to assign grades on the modified Rankin Scale. Stroke 2002;33:2243-46 CrossRef Medline

24. Lyden P. Using the National Institutes of Health Stroke Scale: a cautionary tale. Stroke 2017;48:513-19 CrossRef Medline

25. Pexman JH, Barber PA, Hill MD, et al. Use of the Alberta Stroke Program Early CT Score (ASPECTS) for assessing CT scans in patients with acute stroke. AJNR Am J Neuroradiol 2001;22:1534-42 Medline
26. Adams HP Jr, Bendixen BH, Kappelle LJ, et al. Classification of subtype of acute ischemic stroke: definitions for use in a multicenter clinical trial-TOAST. Trial of Org 10172 in Acute Stroke Treatment. Stroke 1993;24:35-41 CrossRef Medline

27. Zaidat OO, Yoo AJ, Khatri P, et al; STIR Thrombolysis in Cerebral Infarction (TICI) Task Force. Recommendations on angiographic revascularization grading standards for acute ischemic stroke: a consensus statement. Stroke 2013;44:2650-63 CrossRef Medline

28. Hacke W, Kaste M, Bluhmki E, et al. Thrombolysis with alteplase 3 to 4.5 hours after acute ischemic stroke. N Engl J Med 2008;359:1317-29 CrossRef Medline

29. Zhu F, Anadani M, Labreuche J, et al; TITAN Investigators. Impact of antiplatelet therapy during endovascular therapy for tandem occlusions: a collaborative pooled analysis. Stroke 2020;51:1522-29 CrossRef Medline

30. von Kummer R, Broderick JP, Campbell BC, et al. The Heidelberg Bleeding Classification: classification of bleeding events after ischemic stroke and reperfusion therapy. Stroke 2015;46:2981-86 CrossRef Medline

31. Nahab F, Walker GA, Dion JE, et al. Safety of periprocedural heparin in acute ischemic stroke endovascular therapy: the multi MERCI trial. J Stroke Cerebrovasc Dis 2012;21:790-93 CrossRef Medline

32. Gory B, Haussen DC, Piotin M; et al; TITAN investigators. Impact of intravenous thrombolysis and emergent carotid stenting on reperfusion and clinical outcomes in patients with acute stroke with tandem lesion treated with thrombectomy: a collaborative pooled analysis. Eur J Neurol 2018;25:1115-20 CrossRef Medline

33. Nahab F, Kass-Hout T, Shaltoni HM. Periprocedural antithrombotic strategies in acute ischemic stroke interventional therapy. Neurology 2012;79:S174-81 CrossRef Medline

34. Winningham MJ, Haussen DC, Nogueira RG, et al. Periprocedural heparin use in acute ischemic stroke endovascular therapy: the TREVO 2 trial. J Neurointerv Surg 2018;10:611-14 CrossRef Medline

35. Zhu F, Piotin M, Steglich-Arnholm H, et al; TITAN (Thrombectomy In TANdem Lesions) Investigators. Periprocedural heparin during endovascular treatment of tandem lesions in patients with acute ischemic stroke: a propensity score analysis from TITAN registry. Cardiovasc Intervent Radiol 2019;42:1160-67 CrossRef Medline

36. Sallustio F, Motta C, Merolla S, et al. Heparin during endovascular stroke treatment seems safe. J Neuroradiol 2019;46:373-77 CrossRef Medline

37. Anadani M, Spiotta AM, Alawieh A, et al; on behalf of the TITAN (Thrombectomy In TANdem Lesions) Investigators. Emergent carotid stenting plus thrombectomy after thrombolysis in tandem strokes: analysis of the TITAN registry. Stroke 2019;50:2250-52 CrossRef Medline

38. Zhu F, Labreuche J, Haussen DC, t et al; the TITAN (Thrombectomy in Tandem Lesions) Investigators. Hemorrhagic transformation after thrombectomy for tandem occlusions: incidence, predictors, and clinical implications. Stroke 2019;50:516-19 CrossRef Medline

39. Yilmaz U, Körner H, Mühl-Benninghaus R, et al. Acute occlusions of dual-layer carotid stents after endovascular emergency treatment of tandem lesions. Stroke 2017;48:2171-75 CrossRef Medline 